\title{
Al-doped and pure ZnO thin films elaborated by sol-gel spin coating process for optoelectronic applications
}

\author{
(C) M. Maache ${ }^{1}$, T. Devers ${ }^{2}$, A. Chala ${ }^{3}$ \\ ${ }^{1}$ Department of Science of matter, Ziane Achour University, \\ 17000 Djelfa, Algeria \\ ${ }^{2}$ ICMN, IUT Chartres, University of Orléans, \\ 28000 Chartres, France \\ ${ }^{3}$ Department of Science of matter, Mohamed Khider University, \\ 07000 Biskra, Algeria \\ E-mail: moumos2001@gmail.com
}

(Received 8.10.2015. Received after revision 20.03.2017)

\begin{abstract}
Pure and aluminum-doped zinc oxide thin films were grown by spin coating at room temperature. As a starting material, zinc acetate was used. The dopant source was aluminum nitrate; the dopant molar ratio was varied between 1 and $10 \%$. Structural analysis reveals that all films consist of single hexagonal wurtzite phase $\mathrm{ZnO}$, and a preferential orientation along $c$-axis. They have a homogeneous surface. The measurements show that the films are nanostructured. The transmittance is greater than $75 \%$ in the visible region. The band gap energy decreases with the addition of dopant $(\mathrm{Al})$ in prepared thin films and the resistivity decreases significantly.
\end{abstract}

DOI: 10.21883/FTP.2017.12.45182.8078

\section{Introduction}

Semiconductor materials have been extensively investigated because of their unique size dependent optoelectronic, magnetic and electrochemical properties. One of the semiconductors suitable for photovoltaic applications is $\mathrm{ZnO}$ because of its high-electrical conductivity and optical transmittance in the visible region of the solar spectrum [1], which is very important in solar cell fabrications. ZnO-based films have recently been studied in many fields. For example, they can be used as transparent conductors [2-4], piezoelectric devices [5], gas sensors [6], solar cell windows [7] and surface acoustic wave devices [8].

Numerous $\mathrm{ZnO}$ films preparation methods were experienced, such as RF magnetron sputtering [9], chemical vapor deposition CVD [10], spray pyrolysis [11] pulsed laser [12] and the sol-gel process [13-15]. While physical deposition produces films with good electrical and optical properties at lower deposition temperature, it has the disadvantages of a relatively low deposition rate and a high cost for equipment. However, the sol-gel technique offers the possibility of preparing a small as well as large-area coating of $\mathrm{ZnO}$ thin films at low cost for technological applications. The electrical properties of $\mathrm{ZnO}$ film can be modified by heat treatment in $\mathrm{H}_{2}$ atmosphere or by an appropriate doping process [16]. The doping of impurities such as $\mathrm{Al}$, In, $\mathrm{Ga}, \mathrm{B}$ resulted in high electrical conductivity $[16,17]$. By the process of doping aluminum to $\mathrm{ZnO}$, free electrons will be released when zinc is replaced by aluminum, so the increase of carrier concentration can improve the conductivity.

The present work represents an alternative approach to previous studies and describes the pure $\mathrm{ZnO}$ and $\mathrm{Al}$-doped nanocrystals grown on glass substrates by spin coating method. The solutions with few additives were used, that yield stable sols and homogeneous layers with the proper annealing conditions. In this work, the effects of
Al dopant and its concentration on the surface morphology, microstructure and optoelectrical properties of $\mathrm{ZnO}$ thin films, as well as the interrelationship between these properties was investigated. This contribution highlights our efforts to elaborate semiconductor nanostructures for solar technologies and optoelectronic applications.

\section{Experimental}

Nanocrystalline $\mathrm{ZnO}$ films were prepared by a sol-gel process. In our experiments a homogeneous and stable sol was prepared. Zinc acetate dehydrate $\left(\mathrm{Zn}\left(\mathrm{CH}_{3} \mathrm{COO}\right)_{2} \cdot 2 \mathrm{H}_{2} \mathrm{O}\right)$ was used as a starting material. It was dissolved in 2-methoxyethanol $\left(\mathrm{CH}_{3} \mathrm{OCH}_{2} \mathrm{CH}_{2} \mathrm{OH}\right)$, and an appropriate monoethanolamine (MEA: $\mathrm{HOCH}_{2} \mathrm{CH}_{2} \mathrm{NH}_{2}$ ) was added as a stabilizer. The molar ratio of MEA to zinc acetate was maintained at $1: 1$. The dopant source was aluminum nitrate nonahydrate $\left(\mathrm{Al}\left(\mathrm{NO}_{3}\right)_{3} \cdot 9 \mathrm{H}_{2} \mathrm{O}\right)$, and the ratio of aluminum to zinc in the solution was varied in the range of 1 to $10 \mathrm{at} \%$.

After continuous magnetic stirring at $70^{\circ} \mathrm{C}$ for $1 \mathrm{~h}$, a transparent sol of $0.3 \mathrm{M}$ was obtained. The sol was deposited onto microscope glass slide substrates (thickness of $1 \mathrm{~mm}$ ) which were cleaned with detergent TFD4 2\% solution and distilled water, then they were rinsed in ultrasonic bath and finally dried with $\mathrm{N}_{2}$ air. In this experiment, different values of dopant concentration $(1,3,5$, and 10 at $\%)$ were prepared. The coating solution approx $0.2 \mathrm{ml}$ was dropped and spin-coated with $3000 \mathrm{rpm}$ for 35 seconds (the spinner reached $3000 \mathrm{rpm}$ after 5 seconds which was maintained for 25 seconds). In this coating, precursor films were formed first at ambient temperature, and then each coating was followed by subsequent preheating at $250^{\circ} \mathrm{C}$ for 5 minutes in air to evaporate the solvent. The above procedure was repeated (spinning-drying) 5 times. After that, the films were post heated at $450^{\circ} \mathrm{C}$ for $1 \mathrm{~h}$ in the 

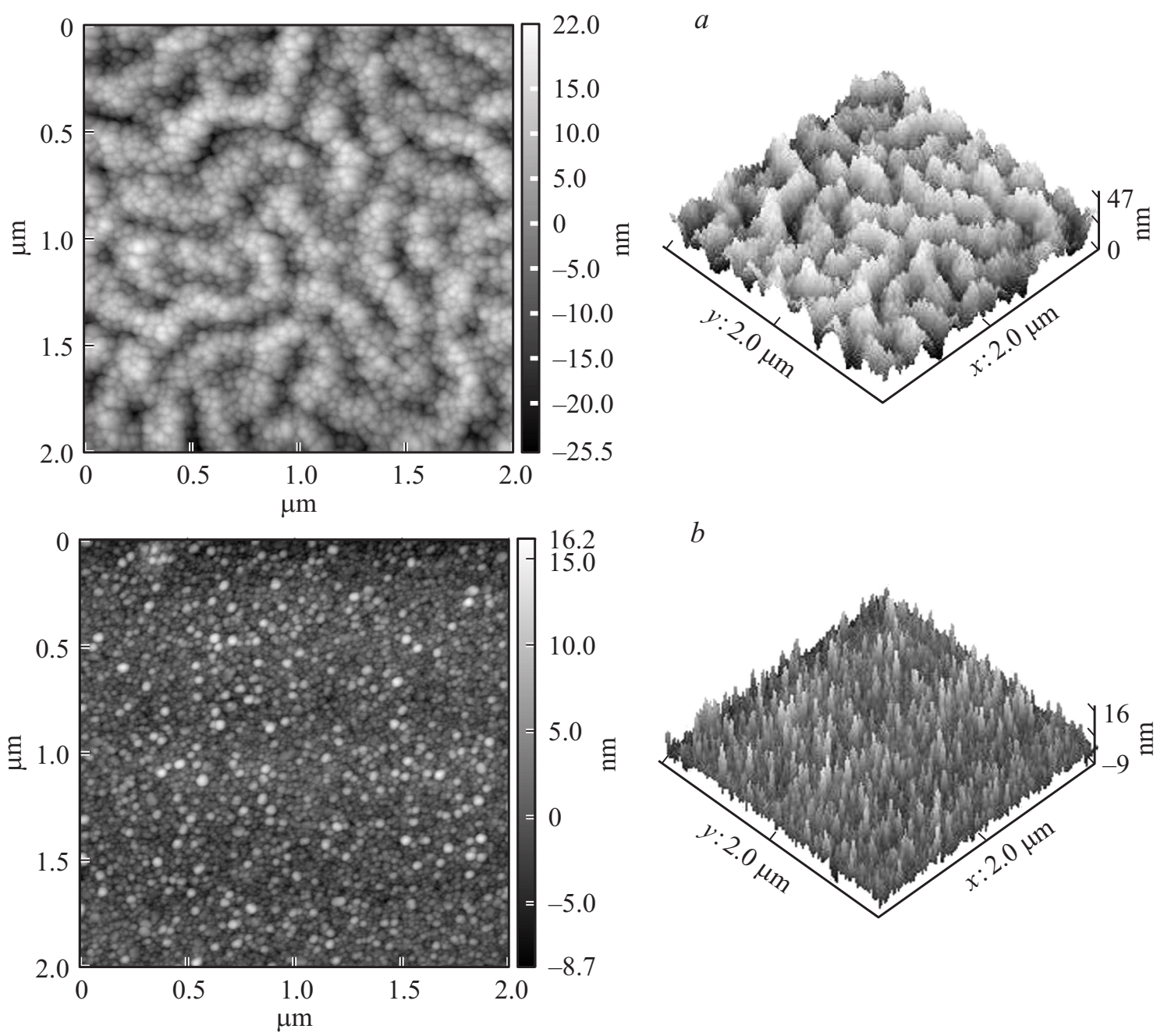

$b$

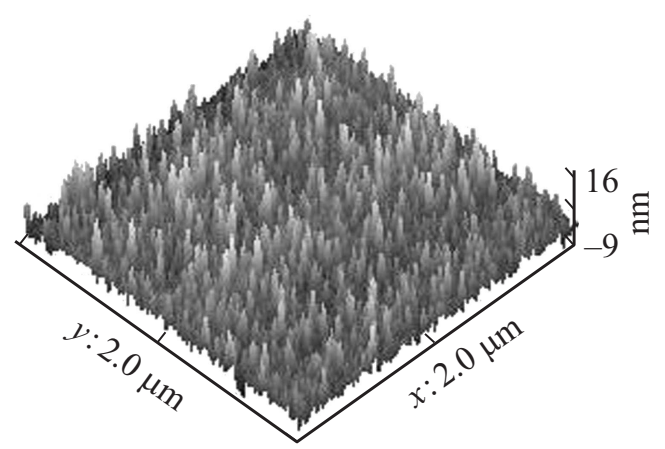

Figure 1. The $2 \mathrm{D}$ and $3 \mathrm{D}$ AFM micrographs of: $a$ - pure $\mathrm{ZnO}$ film annealed at $450^{\circ} \mathrm{C}$ for $1 \mathrm{~h}$ in air. $b-\mathrm{AZO}$ film annealed at $450^{\circ} \mathrm{C}$ for $1 \mathrm{~h}$ in air, with concentration of $5 \mathrm{at} \%$.

furnace. This heat treatment decomposed the precursor film and oxidized it so as to produce $\mathrm{ZnO}$ film. Finally it was left to cool down to room temperature. The choice of these parameters was justified from preliminary investigation.

Finally, the multilayered $\mathrm{ZnO}$ films were obtained for measurements. $\mathrm{ZnO}$ thin films grown by sol-gel spin method were characterized by using a variety of techniques. The samples were characterized for surface topology and to confirm the presence of fine particles using an atomic force microscope (AFM: digital Instrument NanoScope $(R)$ III, Veeco Digital Instruments Version 5.30r2). The structural properties of the films were determined by $X$-ray diffractometer using $\mathrm{Cu} K_{\alpha}$ radiation (wavelength $\lambda=1.54056 \AA$ ) with a Philips $X$-ray diffractometer (X'pert PRO, MPD PANalytical) operated at $40 \mathrm{kV}, 20 \mathrm{~mA}$. The scanning electron microscopic (SEM) images were recorded on a LEO 1430 VP microscope. The transmission electron microscopy (TEM) was undertaken with a Philips CM20 (at an acceleration voltage of $200 \mathrm{kV}$ ). The optical transmission spectra for $\mathrm{Al}: \mathrm{ZnO}$ thin films of different aluminum concentrations was obtained in the ultraviolet (uv)/visible/near infrared (nir) region from 300 to $1000 \mathrm{~nm}$ using a double-beam spectrophotometer (JASKO V-530, UV-VIS Version: 1.53) at room temperature. The thicknesses of thin films were measured with a profilometer (Dektak150 from Veeco). The electrical resistivity of thin films was measured with a four-point probe method.

\section{Results and discussion}

\subsection{Film structure and morphology}

In order to study the effect of aluminum concentration on the microstructural properties of Al-doped $\mathrm{ZnO}(\mathrm{AZO})$ thin films, samples with different values of dopant concentration $(0,1,3,5$, and $10 \mathrm{at} \%)$ were used. The surface of pure and AZO thin films observed has a smooth morphology, and very good adherence to the substrate. The SEM morphology images of AZO thin films deposited by spin coating indicate that the AZO thin films have a compact microstructure, they are very dense and the crystal grains 
Table 1. Parameters of the $X$-ray diffraction peak (002) pattern of AZO films and the values of thickness and band gap energy at different aluminum concentration

\begin{tabular}{|c|c|c|c|c|c|c|}
\hline Samples & $2 \theta\left(^{\circ}\right)$ & $d_{h k l}$-spacing, $\AA$ & FWHM $2 \theta\left(^{\circ}\right)$ & Height, cts & Crystallite sizes, $\mathrm{nm}$ & $\Delta x 10^{-4}, \mathrm{~nm}^{-2}$ \\
\hline $\mathrm{AZO} 0 \%$ & 34.3705 & 2.60926 & 0.3011 & 25062.21 & 27.61 & 13.1 \\
\hline AZO 1\% & 34.3898 & 2.60784 & 0.3346 & 25123.16 & 24.85 & 16.2 \\
\hline AZO 3\% & 34.4549 & 2.60306 & 0.2676 & 1017.39 & 31.08 & 10.4 \\
\hline AZO 5\% & 34.3037 & 2.61419 & 0.2007 & 811.38 & 41.42 & 5.8 \\
\hline AZO $10 \%$ & 34.4292 & 2.60279 & 0.6528 & 953.50 & 12.74 & 61.6 \\
\hline
\end{tabular}

cannot be observed. No significant differences were observed between the surface of pure and doped $\mathrm{ZnO}$ films.

The surface topography of not annealed films of $\mathrm{ZnO}$ was studied using atomic force microscopy (AFM). It shows a film with a corrugated surface and no crystal grain can be observed, which confirm its amorphous structure. A careful observation of the annealed film in Fig. 1, $a$ clearly shows that the nanoparticles are grown and aggregated quickly at high temperature, they became integrated into the nanopores. Although, an increase in the surface roughness mean square (rms) roughness was observed, this is attributed to a better filling of the pores with annealing. As a result the grain size of the annealed film is about $27.66 \mathrm{~nm}$. It confirms the size of the crystallites estimated in XRD (Table 1).

Fig. 1, $b$ presents the surface morphology images of Aldoped $\mathrm{ZnO}$ thin films. As it can be observed, both the diameters and heights of the $\mathrm{ZnO}$ grains are larger as compared to those of AZO thin films. The rms of the films is decreased with $\mathrm{Al}$ loading and thus effectively smooths the surface and exhibits a dense film structure.

$X$-ray diffraction shows $\mathrm{ZnO}$ (zincite) structure with $c$-axis preferred orientation (002). Fig. 2 shows the XRD pattern of five films at different doping concentrations. This crystalline growth of predominately $c$-axis orientation depends on the surface energies of the films, the glass substrate and the interfacial energy between them $[10,18]$.

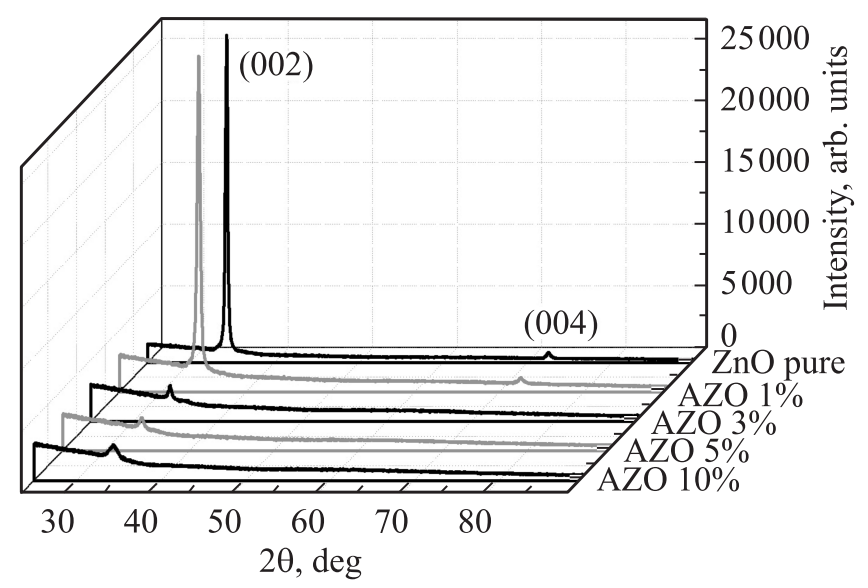

Figure 2. $X$-ray diffraction patterns of AZO films grown by 5 cycle spin-coating.
The surface energy density of the (002) plane is the lowest in a $\mathrm{ZnO}$ crystal, this means that (002) texture of the film may easily be formed [19].

$X$-ray diffraction shows that no diffraction peaks from other species could be detected, which indicates that all the precursors have been completely decomposed during the decomposition process. Another orientation present is (004) which confirmed $c$-axis preferred orientation, (100) and (101) are also seen with comparatively lower intensities. All these peaks reflections can be indexed to the known hexagonal wurtzite structure of $\mathrm{ZnO}$. The analytical method was used to calculate lattice constants $a=b$ and $c$ for $\mathrm{ZnO}$ film, where the distance $d_{h k l}$ is governed by using analytical law [20]:

$$
d_{h k l}=\frac{a}{\sqrt{\frac{4}{3}\left(h^{2}+k^{2}+h k\right)+\frac{l^{2} a^{2}}{c^{2}}}} .
$$

The calculated values of $a$ and $c$ were found to be 3.26 and $5.22 \AA$, respectively. These calculated values are in agreement with files (JCPDS 00-036-1451) for hexagonal $\mathrm{ZnO}$. According to the full width at half-maximum (FWHM) of the diffraction peaks, the mean size of $\mathrm{ZnO}$ nanoparticles $D_{h k l}$ was calculated using a Scherrer's Formula [21]:

$$
D_{h k l}=\frac{k \lambda}{B_{h k l} \cos \theta_{h k l}},
$$

where $D_{h k l}$ is the particle size perpendicular to the normal line of $(h k l)$ plane, $k$ is a constant (it is 0.9$), B_{h k l}$ is the full width at half-maximum of the $(h k l)$ diffraction peak, $\theta_{h k l}$ is the Bragg angle of $(h k l)$ peak and $\lambda$ is the wavelength of $X$-rays used. The dislocation density $\Delta$, which represents the amount of defects in the film was determined from the formula [22]:

$$
\Delta=1 / D_{h k l}^{2} \text {. }
$$

These values corresponding parameters of the (002) peak are listed in Table 1.

No significant differences were observed for the pure and Al-doped $\mathrm{ZnO}$ thin films with the exception of the position of the (002) dominant peak. Some authors attribute this shift to a substitution of zinc by aluminum in the hexagonal lattice [12]. The observed $d$ values are in good agreement with standard $d$ values. The strong intensity and the narrow width of $\mathrm{ZnO}$ diffraction peaks indicate better crystallization 

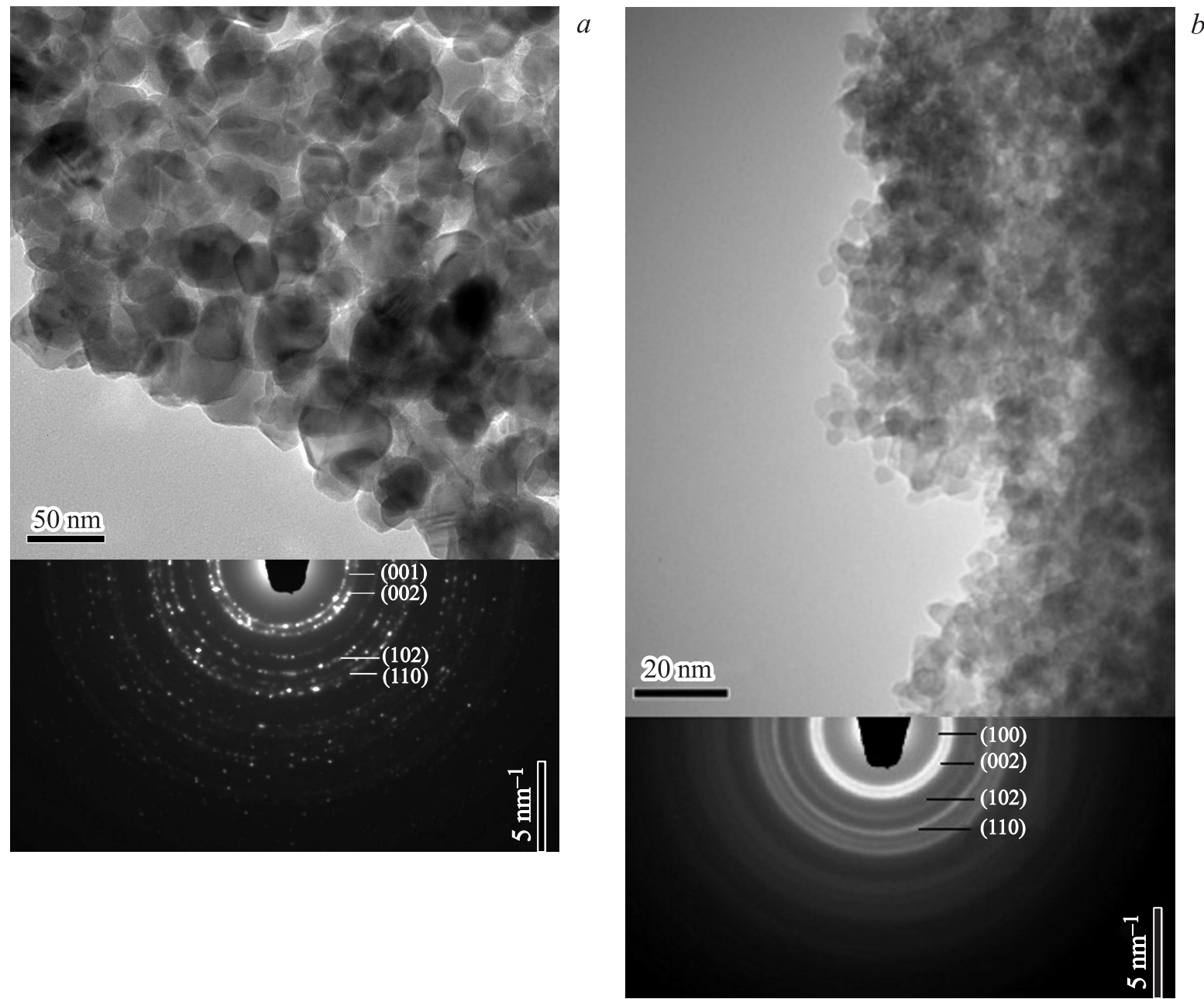

Figure 3. TEM images and the selected-area electron diffraction pattern of: $a$ - pure $\mathrm{ZnO}$ nanoparticles, $b-\mathrm{AZO} 10 \%$ nanocomposite, elaborated by spin coating.

of the film. However, the $\mathrm{ZnO}$ films doped with 1 at $\% \mathrm{Al}$ show a preferred orientation along the (002) plane, it means that doping a small amount of $\mathrm{Al}$ in the $\mathrm{ZnO}$ film promotes $c$-axis orientation. Moreover, the $c$-axis orientation of the $\mathrm{ZnO}$ film doped above $3 \mathrm{at} \% \mathrm{Al}$ is decreased. This indicates that an increase in doping concentration deteriorates the crystallinity of films, which may be due to the formation of stresses by the difference in ion size between zinc and the dopant, and the segregation of dopants in grain boundaries, for the films with high doping concentrations [23].

In order to have more insight on the crystalline structure, the films were analyzed by TEM. Fig. 3, $a$ is a TEM a bright field plane-view image of the pure $\mathrm{ZnO}$ nanoparticles. It can be seen that the nanocrystalline $\mathrm{ZnO}$ particles are uniform and they have sphere-hexagonal shapes with agglomeration. The particles have a size of about $30 \mathrm{~nm}$, which is of the same order of magnitude as the value extracted from the XRD data. The selected-area electron diffraction (SAED) pattern in Fig. 3 displays several diffraction rings consisting of some spots, which are typical of a polycrystalline wurtzite structure. Three important plans of hexagonal structure
(100), (002) and (102) in the form of continuous rings in the reciprocal space. This implies that the nanoparticles have multiple-surface orientations. Selected area electron diffraction pattern recorded on one of doped films shown in Fig. 3, $b$, clearly demonstrates that the film is polycrystalline in nature with a distribution of nano-grained $\mathrm{ZnO}$. Results revealed that the size of particles of the AZO thin films is changed compared to those of the pure $\mathrm{ZnO}$ thin films, and they have a strong agglomeration. The grain size of AZO is of about $7.8 \mathrm{~nm}$, which confirms the DRX and AFM results.

\subsection{Optical transmittance results}

The UV-vis spectra of the films were studied using the optical transmittance measurements which were taken in the spectral region from 300 to $1000 \mathrm{~nm}$. The transmission spectra of $\mathrm{ZnO}$ films deposited under identical spinning conditions but varying the doping ratio are given in Fig. 4. The elaborated films are transparent in the visible range above $400 \mathrm{~nm}$. All the produced films $\mathrm{ZnO}$ and AZO showed a high transmittance $(\sim 75-93 \%)$, some 


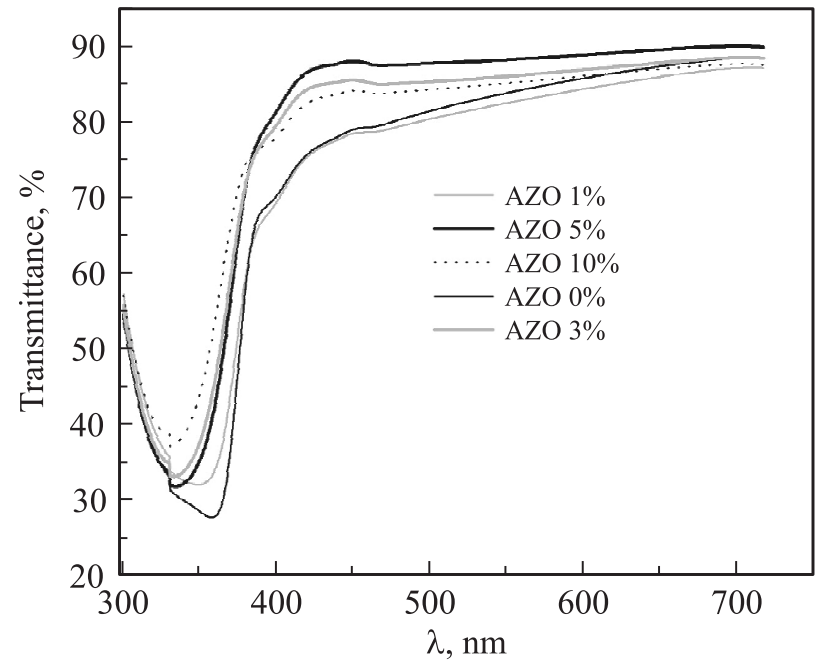

Figure 4. Optical transmittance spectra of $\mathrm{ZnO}$ and $\mathrm{AZO}$ thin films prepared by spin-coating (5 layers) deposited at glass substrate.

authors reported that the use of 2-methoxyethanol and monoethanolamine (MEA), solvents with high boiling point, resulted in transparent $\mathrm{ZnO}$ films with strong preferred orientation. Also the films have sharp ultraviolet absorption edges at $380 \mathrm{~nm}$. This shift can be accounted in terms of the increase in carrier concentration that blocks the lowest states in the conduction band which causes a Burstein Moss effect [24], and enhances the optical band gap. As shown in Fig. 1, the difference in the optical transmittance may be attributed to the larger grain size and the porosity of the films. The low transmittance is due to the segregated $\mathrm{Al}_{2} \mathrm{O}_{3}$ and pores formed in the AZO film during annealing.

The optical band gap was evaluated from the transmission spectra. The absorption coefficient $\alpha$ was evaluated using the measured value of thickness $d$ using Lambert law [25]:

$$
\alpha=\frac{1}{d} \ln \frac{1}{T} .
$$

Where $d$ is the film thickness. The optical absorption coefficient $\alpha$ near the absorption edge is given by [26]:

$$
(\alpha h v)^{2}=A\left(h v-E_{g}\right),
$$

where $A$ is a constant which is related to the effective masses associated with the bands, and $E_{g}$ is the band gap

Table 2. Values of the band gap energy and the resistivity at different aluminum dopant concentration

\begin{tabular}{c|c|c}
\hline Samples & $E_{g}, \mathrm{eV}$ & Resistivity, $\Omega \cdot \mathrm{cm}$ \\
\hline AZO 0\% & 3.42 & 6.704 \\
AZO 1\% & 3.31 & 0.149 \\
AZO 3\% & 3.33 & 0.183 \\
AZO 5\% & 3.36 & 0.277 \\
AZO 10\% & 3.38 & 20.73
\end{tabular}

energy. The direct band gap of $\mathrm{ZnO}$ thin film was estimated by plotting $(\alpha h v)^{2}$ versus the photon energy $h v$, and by extrapolating the linear portion of the graph to the energy axis at $\alpha=0$. The values corresponding $E_{g}$ of the produced films are listed in Table 2.

It can be noticed from the above results that the optical gap of $3.3-3.38 \mathrm{eV}$ for $\mathrm{Al}$ doped $\mathrm{ZnO}$ thin films is in good agreement with values reported in the literature. The difference registered between the gaps of AZO thin films is due to the doping effect on the absorption edge, it appears as a blue shift. The optical band gap shows a slight decrease in the gap value of doped films than the pure $\mathrm{ZnO}$ film; this is in agreement with Burstein-Moss effect, showing the increase of band gap by the doping of Al [27].

\subsection{Electrical properties}

The effect of aluminum doping on the electrical resistivity of $\mathrm{ZnO}$ thin films was studied. The electrical resistivity of AZO films is function of aluminum concentration (Table 2). A strong decrease of the resistivity with Al doping content was observed. The resistivity of the deposited AZO thin films decreases considerably when aluminum is incorporated. At room temperature, the pure $\mathrm{ZnO}$ film has a resistivity of $0.67 \Omega \cdot \mathrm{cm}$. For aluminum doped AZO thin films, the resistivity with 1 at $\% \mathrm{Al}$ dropped down to $1.49 \cdot 10^{-2} \Omega \cdot \mathrm{cm}$, then, a slight increase of the resistivity is observed about 3 and 5 at $\% \mathrm{Al}$ doping.

In particular, the doped $\mathrm{ZnO}$ film and exhibits a minimum resistivity with low doping concentration (1-2) at $\%$ of $\mathrm{Al}[16,28]$. These resistivity values are similar to those reported in the literature for Al-doped $\mathrm{ZnO}$ film synthesized by sol-gel techniques [29]. The decrease in the resistivity with increased $\mathrm{Al}$ concentration can be interpreted as a result of electrons coming from the donor $\mathrm{Al}^{3+}$ ions incorporated as substitution a $\mathrm{Zn}^{2+}$ cation site or in an interstitial position [30].

However, the deterioration of electrical properties in the AZO with large doping concentration films and the excess of $\mathrm{Al}$ seemed to be due to a decrease in the mobility of carriers caused by segregation of $\mathrm{Al}_{2} \mathrm{O}_{3}$ at grain boundaries and partially pore.

\section{Conclusions}

The thin film deposition by sol-gel technique is a chain process where the quality and properties of the final product rely on the intermediate steps. Pure zinc oxide and aluminum doped zinc oxide films were prepared onto glass substrates by spin coating. They were characterized by using a variety of techniques. Morphology of the films showed that they were very smooth. The $X$-ray diffraction pattern of the crystalline AZO thin films reveals the existence of a $\mathrm{ZnO}$ single-phase with a hexagonal wurtzite structure. The XRD pattern consists of a (002) main peak, which is due to $\mathrm{ZnO}$ crystals that grow along the $c$-axis with a high degree of orientation. The thin films were characterized 
by ultraviolet-visible spectrophotometry, which indicate that sol-gel $\mathrm{ZnO}$ films have potential applications such as transparent electrodes in optoelectronic devices. All the films exhibited a transmission of over $75 \%$ in the visible region. The doped films showed a direct transition in the range $3.3-3.38 \mathrm{eV}$. The electrical resistivity of the films strongly depended on the Al concentration. Al-doped films had a lower resistivity than pure films. Under the optimized deposition condition the AZO: $1 \%$ film showed a resistivity of $1.49 \cdot 10^{-2} \Omega \cdot \mathrm{cm}$.

In conclusion, it may be considered that the deposited crystalline $\mathrm{ZnO}$ thin film was suitable for many optical devices, such as solar cells, gas sensors, surface acoustic devices, transparent electrodes, etc. Furthermore, we consider that the electrical properties of the deposited $\mathrm{ZnO}$ thin films will also give good results for these applications and studies on this matter are in progress.

Acknowledgment: The authors are thankful and grateful to Dr. Vayer Maryléne (ICMN: University of Orleans) for AFM measurements, Mrs. Sagot Nadine and Dr. Olivier Veron (PRISME: University Institute of Technology - Chartres) for the technical help they have provided, Dr. Pierre-Henri Aubert (LPPI: University of Cergy-Pontoise) for assistance in thickness and electrical measurements and Mr. Jalabert Dominique (CME: University of Orleans) for the MET measurements.

\section{References}

[1] S.J. Pearteon, D.P. Norton, K. Ip, Y.W. Heo, T. Steiner. Prog. Mater. Sci., 50, 293 (2005).

[2] W. Water, S.-Y. Chu, Y.-D. Juang, S.-J. Wu. Mater. Lett., 57, 998 (2002).

[3] I. Hengel, A. Neisser, R. Klenk, M. ch. Lux-steiner. Thin Sol. Films, 361-362, 458 (2000).

[4] I. Ozerov, D. Nelson, A.V. Bulgakov, W. Marineand, M. Sentis. Appl. Surf. Sci., 212-213, 349 (2003).

[5] X.D. Wang, J.H. Song, J. Liu, Z.L. Wang. Science, 316, 102 (2007).

[6] R. Lalauze, C. Pijolat, S. Vincent, L. Bruno. Sensors Actuators B, 8, 237 (1992).

[7] M. Law, L.E. Greene, J.C. Johnson, R. Saykally, P. Yang. Nature Mater., 4, 455 (2005).

[8] M. Bender, E. Gagaoudakis, E. Douloufakis, E. Natsakou, N. Katsarakis, V. Cimalla, G. Kiriakidis, E. Fortunato, P. Nunes, A. Marques, R. Martins. Thin Sol. Films, 418, 45 (2002).

[9] M. Jiang, X. Liu. J. Mater. Sci.: Mater. Electron., 20, 972 (2009).

[10] H. Deng, J.J. Russell, R.N. Lamb, B. Jiang. Thin Sol. Films, 458, 43 (2004).

[11] T.V. Vimalkumar, N. Poornima, C. Sudha Kartha, K.P. Vijayakumar. Appl. Surf. Sci., 256, 6025 (2010).

[12] H. Kim, A. Piqué, J.S. Horwitz, H. Murata, Z.H. Kafafi, C.M. Gilmore, D.B. Chrisey. Thin Sol. Films, 377-378, 798 (2000).

[13] M. Sahal, B. Hartiti, A. Ridah, M. Mollar, B. Marí. Microelectronics J., 39, 1425 (2008).
[14] J.H. Lee, K.H. Ko, B.O. Park. J. Cryst. Growth, 247, 119 (2003).

[15] L. Zhifeng, J. Zhengguo, L. Wei, L. Xiaoxin. J. Sol-Gel Sci. Techn., 40, 25 (2006).

[16] P. Nunes, E. Fortunato, P. Tonello, F. Braz Fernandes, P. Vilarinho, R. Martins. Vacuum, 64, 281 (2002).

[17] N. Baydogan, O. Karacasu, H. Cimenoglu. J. Sol-Gel Sci. Techn., 61 (3), 620 (2012).

[18] H.Y. Bae, G.M. Choi. Sensours Actuators B, 55, 47 (1999).

[19] K.L. Chopra, S. Major, D.K. Pandaya. Thin Sol. Films, 102, 1 (1983).

[20] C.S. Barrett, T.B. Massalski. Structure of Metals (Pergamon Press, Oxford, 1980).

[21] A. Guinier. Théorie et Technique de la Radiocristallographie (Dunod, Paris, 1964).

[22] J. Nishino, S. Ohshio, K. Kamata. J. Am. Ceram. Soc., 75, 3469 (1992).

[23] M. Ohyama, H. Kozuka, T. Yoko. J. Ceram. Soc. Jpn., 104, 296 (1996)

[24] E. Burstein. Phys. Rev., 93, 632 (1954).

[25] D. Bao, X. Wu, L. Zhang, X. Yao. Thin Sol. Films, 350, 30 (1999).

[26] G. Kim, J. Bang, Y. Kim, S.K. Rout. S.I. Woo. Appl. Phys. A, 97, 821 (2009).

[27] F.K. Shan, Y.S. Yu. J. Eur. Ceram. Soc., 24, 1869 (2004).

[28] S.B. Majumder, M. Jain, P.S. Dobal, R.S. Katiyar. Mater. Sci. Eng. B, 103, 16 (2003).

[29] S.Y. Kuo, W.C. Chen, F.I. Lai, C.P. Cheng, H.C. Kuo, S.C. Wang, W.F. Hsieh. J. Cryst. Growth, 287, 78 (2006).

[30] S.S. Lin, J.L. Huang, P. Šajgalik. Surf. Coat. Techn., 185, 254 (2004).

Редактор K.V. Emtsev 